\title{
Immunoregulatory Role of GM-CSF in Pulmonary Tuberculosis
}

\author{
Zissis C. Chroneos ${ }^{1, *}$ and Chinnaswamy Jagannath ${ }^{2}$ \\ ${ }^{1}$ Department of Pediatrics, Center of Inflammation, \\ Host Defense and Lung Disease Research, \\ The Pennsylvania State University College of Medicine, Hershey, PA \\ ${ }^{2}$ Department of Pathology and Laboratory Medicine, \\ University of Texas Health Sciences Center at Houston \\ Houston, TX \\ USA
}

\section{Introduction}

\subsection{Tuberculosis}

Tuberculosis is mainly an infectious disease of the lung $(1,2)$. Pulmonary tuberculosis continues to devastate the lives of millions of people worldwide, despite the availability of potent antibiotics against the causative pathogen Mycobacterium tuberculosis (3, 4). Eight to ten million new cases of clinical M. tuberculosis infection are diagnosed yearly, and the death toll due to tuberculosis has remained above 1.7 million people annually over the last two decades. The vast majority of $M$. tuberculosis infections occur in immuno-competent individuals $(4,5)$. Populations in Southeast Asia and sub-Saharan Africa are particularly vulnerable to the disease $(3,6)$. HIV co-infection and the recent emergence of drug resistant strains of $M$. tuberculosis have contributed to the escalation of tuberculosis in recent years (4, 7-9). M. tuberculosis infection exhibits a complex life cycle driving the development of primary, latent, and post-primary tuberculosis in the human host $(2,5,10-12)$.

Primary tuberculosis is a granulomatous immune process that effectively contains $M$. tuberculosis within a few weeks after initial infection (1, 10, 13-15). Primary infection begins when previously uninfected individuals inhale aerosol droplets containing a few $M$. tuberculosis organisms that invade alveolar macrophages, epithelial cells, and dendritic cells in the distal airway mucosa. Mycobacteria arrest phagolysosome fusion and proliferate intracellularly in alveolar macrophages (16). The fate of mycobacteria in lung epithelial cells is not understood, but these cells are thought to participate in granuloma formation $(17,18)$, mycobacterial dissemination (19) and local antigen presentation to T lymphocytes (20). Infected dendritic cells migrate to regional lymph nodes resulting in activation and

\footnotetext{
* Original work presented here represents ten years of collaborative research between Zissis C. Chroneos in his previous position at the University of Texas Health Science Center at Tyler and Chinnaswamy Jagannath at the University of Texas Health Science Center at Houston.
} 
migration of Th1 $\mathrm{T}$ lymphocytes back to the lung halting mycobacterial proliferation through intercellular contact with infected alveolar macrophages $(21,22)$. Dissemination of live mycobacteria or transport of mycobacterial antigens to peripheral immune organs by macrophages and dendritic cells establishes potent anti-mycobacterial immunity at the periphery (23-26). Elaboration of key cytokines such as TNF $\alpha$, IL-12, and IFN $\gamma$ and chemokines drive formation of granulomas at sites of infection (27). Granulomas evolve into caseating lesions containing mycobacteria within a central core of lipid and activated foamy macrophages enclosed by layers of epithelioid cells and lymphocytes. Foamy macrophages undergo necrosis and calcification killing most $M$. tuberculosis organisms. The source of lipid causing foam cell formation is not established but may involve uptake of alveolar type II epithelial cell-derived surfactant lipids or adjoining adipose tissue (17). Healing of caseous lesions represents resolution of the primary infection which occurs asymptomatically in most immuno-competent individuals $(2,28)$.

M. tuberculosis is not completely eradicated by primary cell-mediated immunity causing latent tuberculosis infection (LTBI) $(10-12,29)$. LTBI is thought to result from mycobacterial adaptation to the hypoxic lipid environment of caseous granulomas (14, 30, 31). A small number of bacteria survive presumably in macrophage phago-lysosomes in a non-replicative or dormant state. Cell-mediated immunity established during primary infection exerts lifelong control of LTBI in the host. Immunosuppressive therapy aimed at treating inflammatory and autoimmune diseases by targeting $\mathrm{TNF} \alpha$, a crucial host factor in control of LTBI, results in reactivation of tuberculosis in latently infected individuals (29). LTBI is diagnosed using the purified protein derivative (PPD) skin test or interferon gamma release assays that measure mycobacterial antigen-specific recall responses of cell-mediated immunity. LTBI is present in over 3 billion people worldwide. Recent imaging observations in humans and non-human primates indicate that LTBI represents active rather than dormant subclinical infection contained within heterogeneous granulomatous lesions in the same host (11).

Reinfection or reactivation of LTBI results in development of post-primary also called secondary tuberculosis in the lungs of individuals that have already developed robust immunity to the primary infection $(2,5)$. For reasons that are not understood, over-activation or perhaps unanticipated activation of the pulmonary immune system may steer the development of post-primary tuberculosis in the face of strong anti-tuberculosis immunity at the periphery. Individuals with LTBI have a 10\% life-time risk of developing post-primary tuberculosis. Interestingly, post-primary tuberculosis occurs mainly in young adults aged 1540 years old $(4,5)$. Post-primary tuberculosis is responsible for $80 \%$ of clinical cases of tuberculosis and is the source of most transmission of the infection in the community. The more widely reported account of secondary tuberculosis pathology in the post-antibiotic era is that liquefaction of caseous granulomas results in formation of cavities. According to Hunter (5), however, post-primary tuberculosis manifests mainly as a lipid broncho-pneumonia, rather than a granulomatous disease process, that resolves spontaneously in most cases without further medical intervention. The view of post-primary tuberculosis as a lipid pneumonia agrees with the description of the disease reported by pathologists in the preantibiotic era when tuberculosis was rampant in the Western World. Hunter's observations are based on lung autopsies from patients who succumbed to tuberculosis but did not receive antibiotic therapy, reevaluation of specimen from the John Hopkins tuberculosis historical repository, and post-mortem lung biopsies of tuberculosis patients from Russia. Unresolved 
post-primary tuberculosis lipid pneumonia progresses into caseous necrotic lesions in which mycobacteria reach high numbers. Caseous necrosis results in formation of cavities that release necrotic material along with large numbers of Mycobacterium tuberculosis organisms into main stem bronchi. Coughing then expels $M$. tuberculosis into the atmosphere completing the cycle of airborne transmission of the infection to other members of the community. Individuals with productive cavities but with minimal clinical symptoms can transmit the disease for many years before becoming seriously ill (5).

Understanding geographical differences in immune responses to tuberculosis is essential for the rational design of effective vaccines against tuberculosis $(4,6,32)$. Exposure to higher infection loads in countries where tuberculosis is endemic may contribute to immune exacerbations that increase the risk for development of active tuberculosis infection. Infection with helminths and environmental mycobacteria in developing countries is thought to cause immunological predisposition to active tuberculosis driven by a mixed Th1/Th2 cell-mediated immune response that also renders BCG vaccination ineffective (6, 32-35). Helminth infections are prevalent in areas of the world were tuberculosis is also endemic. Helminths were shown to diminish the efficacy of the BCG vaccine. Co-infection of mice with the helminth Nippostrongylus brasiliensis and Mycobacterium tuberculosis increased mycobacterial burden in the lungs due to accumulation of alternatively activated macrophages. The effect of helminth infection was abrogated in mice lacking the IL-4 receptor IL-4R $\alpha$ indicating that IL-4 drives accumulation of alternatively activated macrophages with reduced capacity to control $M$. tuberculosis infection even in the presence of robust Th1 cell-mediated immunity (35).

The role of GM-CSF in the broader context of vaccine development in the developing world where tuberculosis is an endemic disease is not yet understood. Monitoring of GM-CSF levels as a product of poly-functional $\mathrm{T}$ lymphocytes following BCG vaccination was adopted only recently (36). BCG vaccination of infants and children is effective but does not provide protection beyond adolescence and exhibits variable efficacy when administered in adults $(37,38)$. The failure of BCG vaccines to protect against tuberculosis in developing countries has confounded clinical and basic researchers for many years $(38,39)$. By contrast, BCG vaccination provides lasting protection in $80 \%$ of individuals in developed countries $(33,37)$. It is possible that primary infection is the predominant form of tuberculosis in developed countries where BCG vaccination works, whereas post-primary tuberculosis is the major form of infection in endemic countries were BCG vaccination does not work. GMCSF has been used in a variety of formulations and boosting strategies to enhance BCG priming of anti-tuberculosis cell-mediated immunity with promising results (40-45). So far, GM-CSF has been shown to enhance T cell responses and provide temporary benefit against primary infection with $M$. tuberculosis in pre-clinical models (41).

\section{GM-CSF functions in the lung}

GM-CSF is crucial for pulmonary homeostasis as a modulator of alveolar macrophage differentiation $(46,47)$. GM-CSF signals through a bi-component receptor of $\alpha$ and $\beta c$ subunits mediating concentration-dependent functions of GM-CSF in macrophages and other cell types. Assembly of the GM-CSF receptor heterodimer into hexameric or dodecameric forms underlies pleiotropic effector functions of GM-CSF (48). Secreted 
constitutively at low levels by alveolar type II epithelial cells, GM-CSF is required for terminal alveolar macrophage differentiation $(47,49)$. Disruption of GM-CSF in both humans and mice results in development of alveolar proteinosis, a disease characterized by excessive accumulation of surfactant proteins and lipids in the alveolar space $(50,51)$. In the absence of GM-CSF, alveolar macrophages are arrested at an immature state with reduced capacity to internalize and catabolize surfactant $(47,52,53)$. Normally, alveolar macrophages contribute $20-50 \%$ of surfactant catabolic activity in alveoli (54). In addition to surfactant catabolism, GM-CSF regulates phagocytosis and innate immune responses in alveolar macrophages $(47,55)$. GM-CSF modulates expression of the transcription factors PU.1 and PPAR $\gamma$. Optimal levels of PU.1 as maintained by GM-CSF are crucial for differentiation and multiple immune functions of alveolar macrophages $(46,47,55-57)$ while in addition to PU.1, expression of PPAR $\gamma$ is necessary for the catabolism of surfactant lipids by alveolar macrophages (58-60).

GM-CSF coordinates regulatory functions of alveolar macrophages that modulate activation of pulmonary mucosal immunity and protection of the distal airway epithelium from inflammatory stimuli (61-63). GM-CSF regulates, recruitment, activation, and expansion of alveolar macrophages, alveolar type II epithelial cells, and dendritic cells (47, 64-66). Under normal conditions alveolar macrophages maintain immune homeostasis by inhibiting activation of $\mathrm{T}$ lymphocytes by innocuous antigens. Anti-inflammatory mediators such TGF $\beta$, IL-10, nitric oxide, and constituents of pulmonary surfactant, SP-A, SP-D, and lipids contribute to the suppressive activities of alveolar macrophages $(67,68)$. In particular, the SP-A receptor SP-R210 moderates proliferation of lymphocytes in peripheral blood mononuclear cells of PPD+ individuals (69). High levels of GM-CSF inhibit the ability of alveolar macrophages to suppress mucosal immunity (63), representing an important switch mechanism between steady-state conditions and activation of cell-mediated immunity in the lung. On the other hand, optimal alveolar macrophage differentiation as normally maintained by epithelial derived GM-CSF in the lung, is necessary for appropriate innate immune responsiveness of alveolar macrophages. For example, induction of TNF $\alpha$ secretion by alveolar macrophages in response to LPS results in paracrine stimulation of high levels of GM-CSF by alveolar type II epithelial cells. High levels of GM-CSF stimulate proliferation of alveolar type II epithelial cells protecting the integrity of the alveolar epithelial barrier during acute inflammation (70).

\section{GM-CSF in treatment of tuberculosis}

Pre-clinical studies in animal models have shown that GM-CSF enhances the effectiveness of current vaccines against Mycobacterium tuberculosis (42). Studies in GM-CSF-deficient (GM-/-) mice showed that GM-CSF is necessary for the development of cell-mediated immunity and formation of granulomas against primary $M$. tuberculosis infection in the lung $(71,72)$. Prior vaccination of mice with GM-CSF-secreting Bacillus Calmette Guerin (BCG) reduced pulmonary $M$. tuberculosis numbers up to 100 -fold when administered locally $(41,42)$. The best protection was achieved when BCG-GM-CSF was delivered directly to the lung.

Systemic administration of high levels of GM-CSF, however, reduced anti-tuberculosis immunity in mice (73). Furthermore, GM-CSF-deficient mice in which GM-CSF is constantly secreted at high levels by lung epithelial cells $\left(\mathrm{SP}-\mathrm{C}-\mathrm{GM}^{+/+}\right)$are resistant to the infection initially but do not sustain long-term protective immunity against tuberculosis (71, 72), 
suggesting that high levels of GM-CSF impact cell-mediated immunity in the chronic phase of the disease. On the other hand, lack of GM-CSF in mice was detrimental for survival against virulent $M$. tuberculosis Rv (74) and Erdman strains (72). These findings indicate that GM-CSF expression impacts host resistance to tuberculosis at different stages of the infection.

Remarkably, neither GM-CSF deficiency nor constitutive over-secretion of GM-CSF influence clearance of the vaccine strain $M$. bovis BCG (71). Similarly, clearance of BCG and BCG-GM-CSF expressing strains were not different in WT mice (41). In a related study, pulmonary clearance of Mycobacterium avium was similar between WT and GM- $/$ mice, despite decreased activation of macrophages in the absence of GM-CSF (75). Both absence or high levels of GM-CSF disrupted normal granuloma formation in GM-/- and SP-C-GM+/+ but did not impact clearance of pulmonary BCG infection (71). Furthermore, abnormal levels of GM-CSF did not impair secretion of IL-12p40 in response to BCG infection in GM/- and SP-C-GM+/+ mice (71). IL-12p40 is secreted by dendritic cells and is crucial for Th1 cell-mediated immunity against tuberculosis $(27,76,77)$. To this extend, lack of GM-CSF did not alter the ability of BCG to induce IL-12p40 (71). BCG infection in the presence of high levels of GM-CSF, however, generated an early IFN $\gamma$ burst in SP-C-GM+/+ mice compared to WT and $\mathrm{GM}-/-$ mice 9 days after infection (Figure 1), and remained at the same high levels over the course of the experiment. In contrast, IFN $\gamma$ increased gradually in WT mice reaching similar levels as SP-C-GM ${ }^{+/+}$mice by 29 days after BCG infection. IFN $\gamma$ levels in $\mathrm{GM} /$ - lungs also increased gradually but were significantly lower than both WT and SP-C$\mathrm{GM}^{+/+}$mice. The kinetics of IFN $\gamma$ secretion in WT mice (Figure 1) correlates with the development of granulomatous inflammation following BCG infection (71). These studies indicate that GM-CSF modifies the initial IFN $\gamma$ response to BCG vaccination.

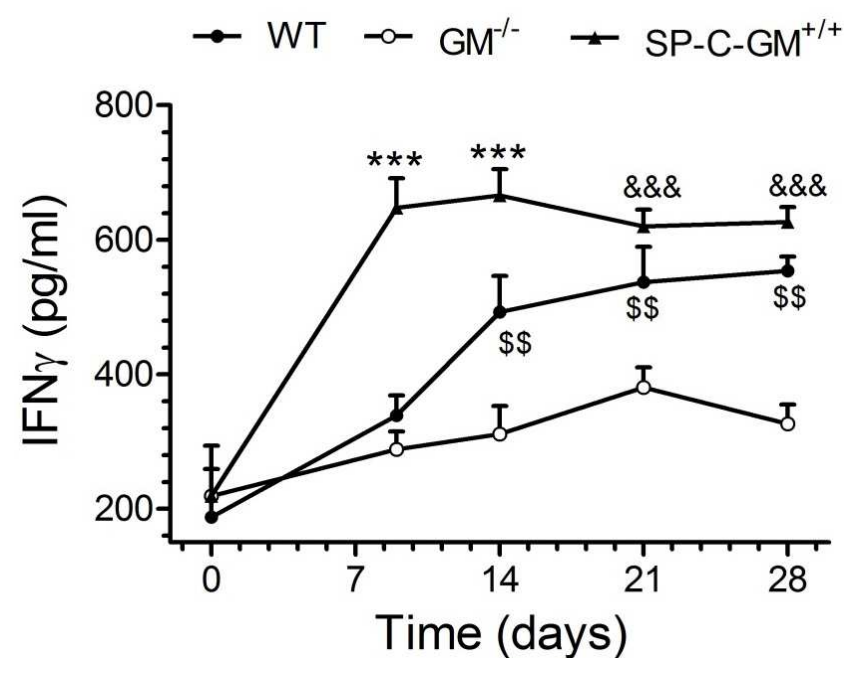

Fig. 1. GM-CSF modulates IFN $\gamma$ levels in response to $M$. bovis BCG infection.

$\mathrm{WT} \mathrm{GM}^{-} /$, and SP-C-GM+/+ mice were infected with $1.5 \times 10^{7} \mathrm{cfu}$ of $\mathrm{M}$. bovis BCG via the intranasal route. The concentration of IFN $\gamma$ was measured by ELISA in lung homogenates at indicated times after infection. ${ }^{* * *} \mathrm{p}<0.001$ compared to WT, GM-/-; \&\&\& $\mathrm{p}<0.001$ compared to $\mathrm{GM} /-; \$ \$ p<0.01$ compared to $\mathrm{GM}-/$. Data shown are means \pm S.E.M. $n=9$ for $\mathrm{WT}, \mathrm{n}=10$ for $\mathrm{GM}^{-} /$, and $\mathrm{n}=6$ for $\mathrm{SP}-\mathrm{C}-\mathrm{GM}^{+/+}$mice. 
Differences in GM-CSF levels alter long-term immune responses to BCG vaccination. ELISA assays compared levels of inflammatory mediators in the lungs of $\mathrm{GM} /$ - and $\mathrm{SP}-\mathrm{C}-\mathrm{GM}^{+/+}$ mice at 53 and 75 days after infection with BCG (Figure 2). Figure 2A shows that GM-/- and SP-C-GM ${ }^{+/+}$mice maintained similar levels of IFN $\gamma 53$ and 75 days after infection with BCG.


Fig. 2. High levels of GM-CSF promote Th2 polirization after $M$. bovis BCG infection. WT, GM- $/$, and SP-C-GM+/+ mice were infected with $1.5 \times 10^{7} \mathrm{cfu}$ of $M$. bovis BCG via the intranasal route. The concentrations of IFN $\gamma$, TNF $\alpha$, Il-2, IL-4, IL-10, and MCP-1 were measured by ELISA in lung homogenates at 53 and 75 days after infection. ${ }^{* * *} \mathrm{p}<0.001$ compared to GM- $/$. Data shown are means \pm S.E.M. $n=4$ for all mice. 
The levels of TNF $\alpha$, however, were significantly higher in the lungs of SP-C-GM+/+ mice compared to $\mathrm{GM}^{-} /$- mice 53 days after infection, consistent with increased macrophage activation in the GM-CSF over-secreting mice (Figure 2B). The level of TNF $\alpha$ in SP-C-GM+/+ mice, however, decreased 75 days after intranasal immunization with BCG and was similar to $\mathrm{GM}^{-/-}$mice (Figure 2B), indicating suppression of macrophage activation in SP-C-GM ${ }^{+/+}$ mice at the later time point. Correspondingly, the levels of IL-2 (Figure 2C), IL-4 (Figure 2D), and IL-10 (Figure 2E) increased significantly 75 days after BCG immunization of SP-C- $\mathrm{GM}^{+/+}$mice, indicating proliferation of $\mathrm{T}$ lymphocytes secreting immunosuppressive cytokines. The increase in IL-4 secretion suggests that high levels of GM-CSF in the context of BCG immunization results in activation of Th2 cell-mediated immunity in the long term. Furthermore, Figure 2F shows significantly increased levels of MCP-1 53 days after immunization with BCG in SP-C-GM+/+ mice that remained elevated at 75 days. MCP- 1 is considered an important biomarker predictive of active TB infection or increased risk for development of active tuberculosis (78-81). In this regard, the SP-C-GM+/+ mice display delayed morbidity compared to $\mathrm{GM} /-$ mice following infection with virulent $M$. tuberculosis; all SP-C-GM ${ }^{+/+}$mice were alive at 53 days but their survival decreased after 70 days $(71,72)$. These results indicate that GM-CSF modifies transitional immune responses to mycobacterial infections between primary and chronic phases of the disease.

\section{GM-CSF coordinates immunopathology with lung resistance to M. tuberculosis}

Why does GM-CSF influence susceptibility to pulmonary M. tuberculosis but not to other mycobacterial species? Histological analysis, mycobacterial localization, and measurements of immune responses of $M$. tuberculosis infected lungs from WT, GM-/- and SP-C-GM+/+ mice provided important insights (71). The previous studies and the findings presented here show that the balance between GM-CSF levels and mycobacterial load underlie the complexity of pathological and host immune responses in tuberculosis.

In WT and SP-C-GM ${ }^{+/+}$mice, the earliest lung response to $M$. tuberculosis infection was the appearance of macrophage aggregates in the interstitial space underlying alveolar epithelial cells 7 days after infection. This early response did not occur in $\mathrm{GM}-1-$ mice whereas interstitial lesions were restored and larger in SP-C- $\mathrm{GM}^{+/+}$mice. Parenchymal interstitial lesions in WT mice had evolved into multicellular structures of epithelioid macrophages interspersed with lymphocytic infiltrates 15 days after infection. The WT lung epithelioid lesions persisted over time in lung parenchyma along with the appearance of highly organized peribronchial and submucosal granulomas containing lymphocyte aggregates and foamy macrophages 15 days onward. Interestingly, formation of epithelioid inflammation in WT mice contrasts the histopathology observed after infection with BCG where only lymphocytic granulomas in peribronchial/submucosal areas were observed (71). Lymphocytic granulomas containing clusters of lymphocytes were small and sparse in BCG infected SP-C-GM ${ }^{+/+}$lungs. The $M$. tuberculosis infected SP-C-GM+/+ however, formed large epithelioid lesions, similar to those observed in WT mice, 15 days after infection but these disintegrated into smaller interstitial lesions over large areas of the lung parenchyma at later time points. Peribronchial and submucosal lymphocytic infiltrates in SP-C-GM ${ }^{+/+}$mice were smaller than in WT mice but contained foamy and epithelioid macrophages. In contrast, the histology of GM-/- lungs, in 
which epithelioid inflammation did not occur at early time points, were characterized by expansion of foamy macrophages consolidating multiple alveoli into necrotic nodules enriched in surfactant lipoprotein 21-28 days after infection $(17,71)$.

The dynamics of mycobacterial infection was visualized using the highly sensitive auramine-rhodamine stain shown on Figure 3. Interstitial lesions were the site of $M$. tuberculosis proliferation in WT mice and were observed at both 15 and 29 days after

\section{A. Localization of M. tuberculosis}

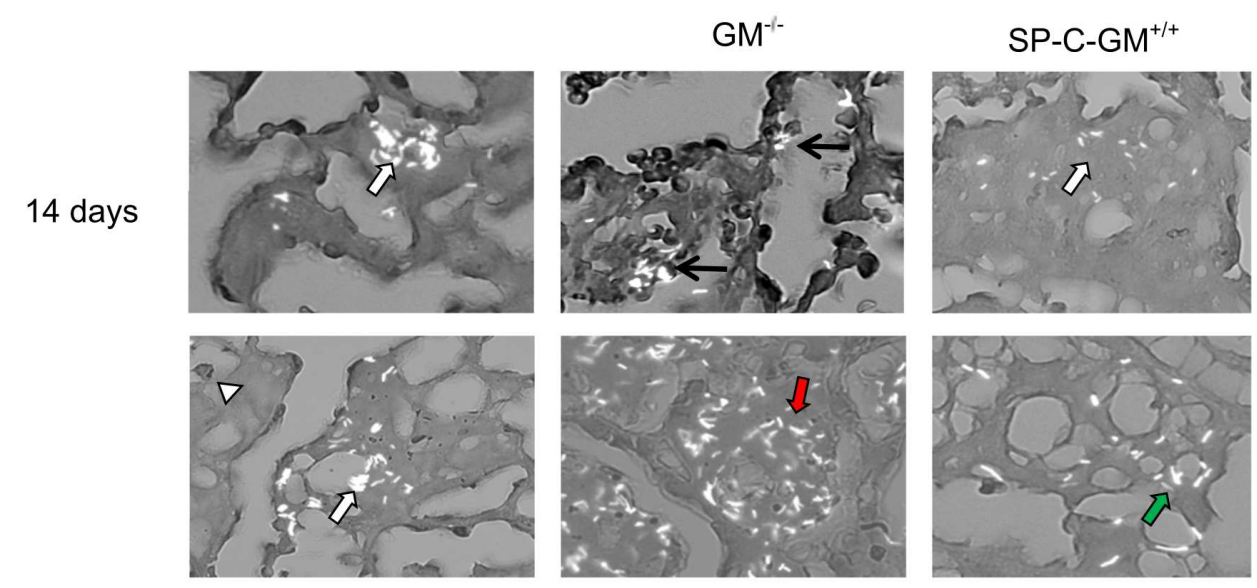

B. Microscopic quantitation of M. tuberculosis

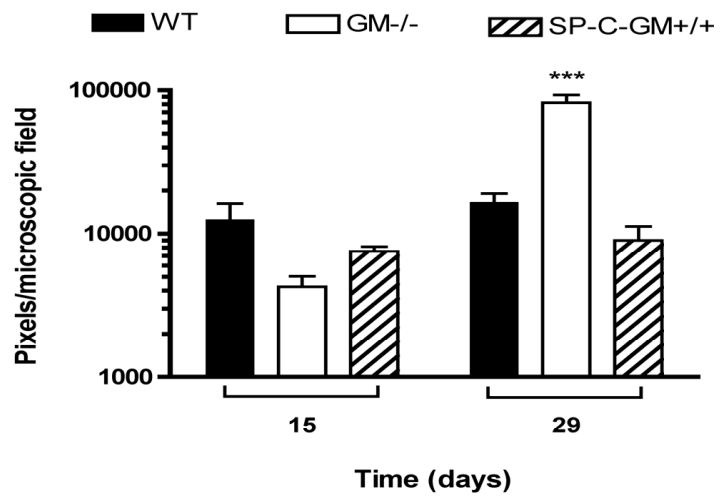

Fig. 3. Effect of GM-CSF on M. tuberculosis localization in the lungs.

A) Localization of M. tuberculosis infection in lung. WT, GM-/-, and SP-C-GM+/+ mice were infected with 100 M. tuberculosis cfu via aerosol. M. tuberculosis organisms were identified in lung tissue section 15 and 29 days after infection using auramine-rhodamine. M. tuberculosis were visualized in distal lung interstitial lesions in both WT and SP-C-GM+/+ mice (white arrow), but were retained in alveolar macrophages and alveolar lumen (open black arrows) 
in $\mathrm{GM}^{-/-}$mice bacilli 15 days after infection. M. tuberculosis were found in smaller but more widespread interstitial lesions in both WT (white arrows) and SP-C-GM+/+ (green arrows) mice. In contrast, $M$. tuberculosis proliferated in intra-alveolar lesions in GM-/- mice 29 days after infection (red arrows). Magnification $\times 40$. B) Microscopic quantitation of $M$. tuberculosis infection in lung. Both WT and SP-C-GM+/+ mice form bacteriostatic lesions while $\mathrm{GM} /$ - mice cannot restrict MTB growth on day 29. Data are means \pm S.E.M ${ }^{* * *} \mathrm{p}<0.001$ in GM-/- vs. all groups.

infection (Fig. 3A, white arrows). Free aggregated M. tuberculosis organisms were observed in the alveolar lumen upon the alveolar epithelium. Some interstitial lesions were devoid of mycobacteria while others contained only a few clusters (Fig. 3A, white arrow heads). Previous assessment of mature lymphocytic granulomas in peribronchial and submucosal areas of the lungs localized single organisms in foamy macrophages in WT and SP-C-GM+/+ mice (17). The mycobacterial burden remained stable between 15 and 29 days in both WT and SP-C-GM+/+ mice (Figure 3B), likely reflecting the balance between poor control in the parenchyma and effective arrest of $M$. tuberculosis in mucosal lesions. In contrast to WT and SP-C-GM ${ }^{+/+}$mice, $M$. tuberculosis organisms infected alveolar macrophages and were seen on the luminal side of alveolar epithelium 15 days after infection (Fig. 3A, open black arrows), but not in the interstitium of $\mathrm{GM}-/$ - mice. The presence of $M$. tuberculosis organisms in parenchymal interstitium of WT and SP-C-GM+/+ nut not in $\mathrm{GM}^{-/-}$mice suggests a potential route of local dissemination of the organism between parenchymal and mucosal sites; there were no differences in dissemination of $M$. tuberculosis to the spleen between the different mouse groups (unpublished data). The parenchymal tropism of $M$. tuberculosis was not evident using the more common Ziehls-Nielsen acid fast stain (unpublished results) but was readily detectable using the auramine-rhodamine stain used on Figure 3. The GM-/mice developed full-blown pulmonary tuberculosis characterized by over a log increase in mycobacterial burden compared to WT and SP-C-GM+/+ mice (Figure 3B) (71). Numerous mycobacteria were located in foamy macrophages in intra-alveolar lipid rich lesions undergoing necrosis (Fig. 3A, red arrows) (17). Necrotic lesions also formed in a fraction of BCG-infected $\mathrm{GM} /$ - mice but these were also rich in neutrophils, were enclosed by healing granulation tissue, and were devoid of BCG organisms. Most GM-/- mice eliminated lung BCG infection without formation of granulomas (71). These results support the concept that primary $M$. tuberculosis infection generates a heterogeneous histological response of epithelioid and lymphocytic granulomas, reflecting the ability of M. tuberculosis to invade the distal lung interstitium at early stage.

That GM-CSF regulates a critical juncture between early parenchymal inflammation and activation of cell-mediated immunity was evidenced by significant differences in IL-12p40 between WT, GM-/-, and SP-C-GM+/+ mice on day 14 (Figure 4A). IL-12p40, produced by dendritic cells, is critical for activation of IFN $\gamma$-secreting T lymphocytes in the lung. IL-12p40 increased significantly between 7 and 14 days in both WT and SP-C-GM+/+ mice but not in $\mathrm{GM}^{-} /$- mice. The levels of IL-12p40 were similar in all mice at later times indicating that, in $\mathrm{GM}^{-} /$- mice IL-12p40 secretion is delayed but not impaired. In GM- $/$mice, IL-12p40 increased in a time-dependent manner after day 14. IL-12p40 increased in a time-dependent manner in WT mice that seemed to equilibrate by day 29 , but in SP-C-GM+/+ mice peak IL$12 \mathrm{p} 40$ levels were observed on day 14 . The concentration of IFN $\gamma$ was significantly higher in SP-C-GM ${ }^{+/+}$mice 7 days after infection compared to WT and $\mathrm{GM}^{-/-}$mice, but not different 

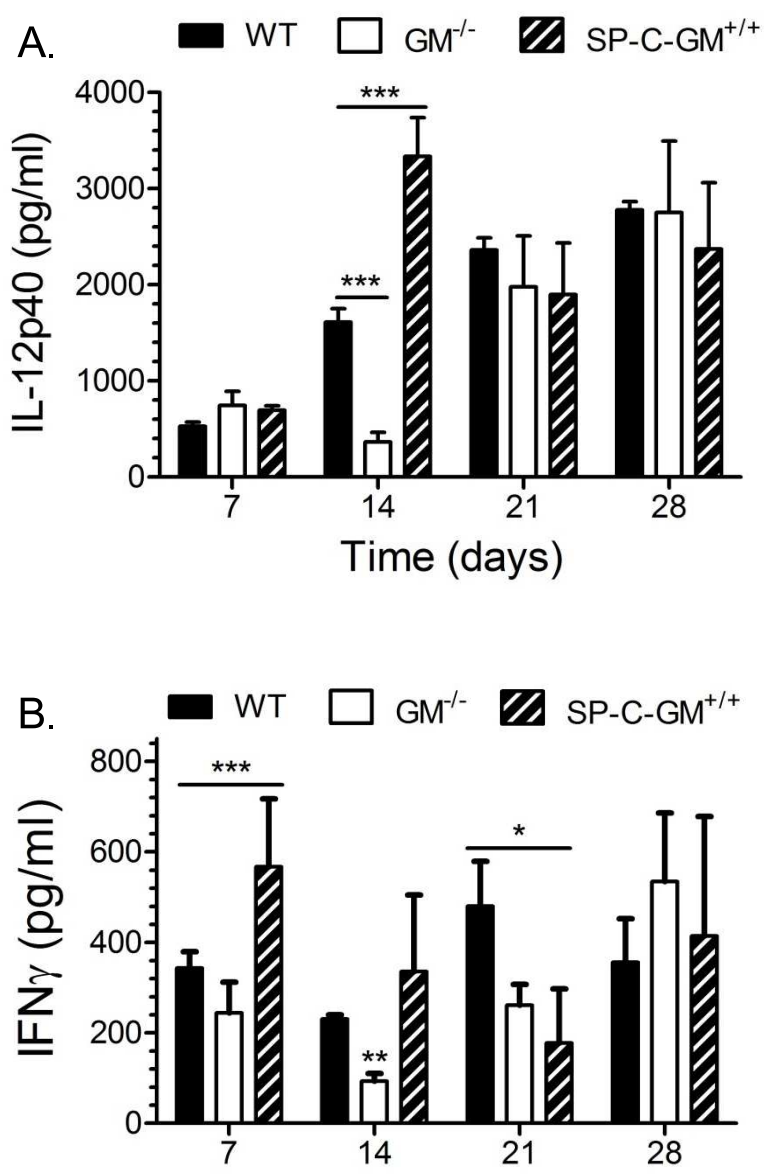

Fig. 4. GM-CSF modulates secretion of IL-12p40 and IFN $\gamma$ in M. tuberculosis infection. WT, GM-/-, and SP-C-GM+/+ mice were infected with $100 \mathrm{M}$. tuberculosis cfu via aerosol. Lung IL-12p40 (A) and IFN $\gamma$ (B) were measured in lung homogenates by ELISA. IL-12p40 and IFN $\gamma$ were attenuated in GM-/- mice on day 14 . Significant differences in IL-12p40 were found on day 7 and 21: *p<0.01 GM-/- vs WT and SP-C-GM+/+ on day 14, ${ }^{* *} \mathrm{p}<0.02$ SP-C$\mathrm{GM}^{+/+}$vs WT and $\mathrm{GM}^{-/-}$on day $21 .{ }^{*} \mathrm{p}<0.001$ SP-C-GM+/+- vs WT and $\mathrm{GM}^{-/-}$on day 7. Data are means \pm S.E.M. $n=4-6$ for all groups.

between WT and GM-/- mice (Figure 4B). The level of IFN $\gamma$ was lower in GM-/- mice 15 days after infection and significantly below the levels of WT and SP-C-GM+/+ mice at this stage of infection. Subsequently, IFN $\gamma$ plateaued 22 days after infection in WT mice. The highest amount of IFN $\gamma$ in $\mathrm{GM}^{-} /$- mice was measured 29 days after infection, indicating delayed activation of $\mathrm{T}$ lymphocytes consistent with the IL-12p40 results on Figure 4A. Induction of IFN $\gamma$ in SP-C-GM ${ }^{+/+}$mice occurred early but subsequently was found to be variable and at overall lower levels (Figure 4B). The effect of different GM-CSF levels in kinetics of lung CD4+ and CD8+ T lymphocytes following $M$. tuberculosis infection are shown on Figure 5. In 


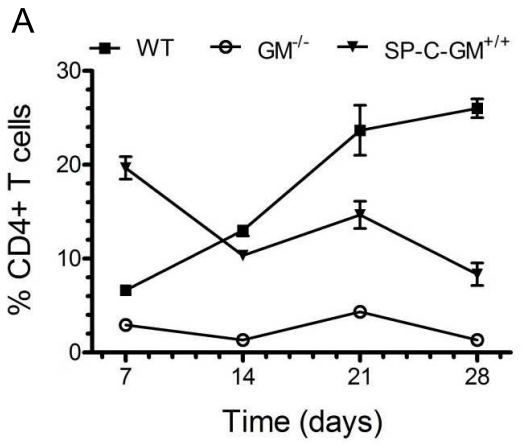

C

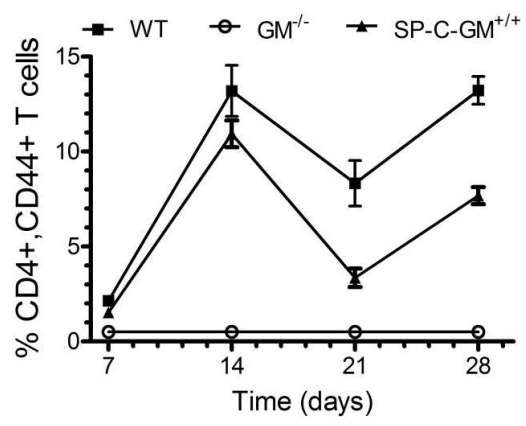

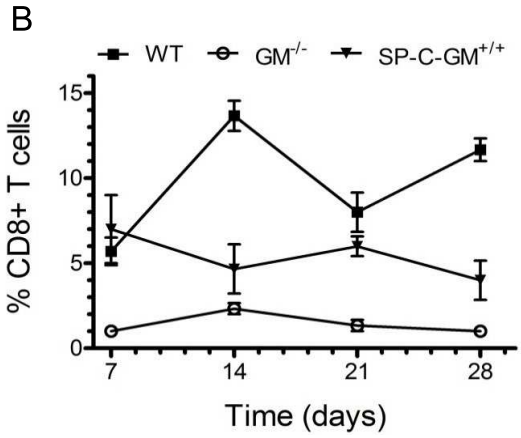

D

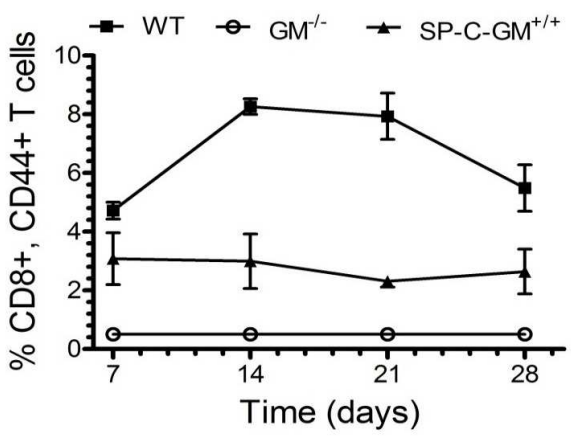

Fig. 5. GM-CSF regulates activation of T lymphocytes in the lung.

WT, GM-/, and SP-C-GM+/+ mice were infected with $100 \mathrm{M}$. tuberculosis cfu via aerosol. Lungs were enzymatically dispersed into cell suspensions at indicated times after infection and lymphocytes analyzed by flow cytometry. The content of CD4+ (A), CD8+ (B) T lymphocytes were obtained by gating. Activated CD4+ (C) and CD8+ (D) T lymphocytes were obtained by staining cells with CD44 antibodies. Data are means \pm S.E.M. $n=4$ for all groups.

WT mice, lung CD4+ $\mathrm{T}$ lymphocytes increased in a time-dependent manner reaching an apparent plateau 28 days after infection (Figure 5B). In contrast, Figure 5B shows abnormal CD4+ T lymphocyte kinetics in SP-C-GM ${ }^{+/+}$lungs with early recruitment 7 days after $M$. tuberculosis infection that equilibrated at lower levels 7-29 days after infection. Compared to WT mice, the CD8+ T lymphocyte content did not change over time in SP-C-GM+/+ lungs (Figure 5B). Despite the early influx of CD4+ T lymphocytes in SP-C-GM+/+ lungs, activation of CD4+ T lymphocytes, as indicated by expression of CD44, was similar in WT and SP-C$\mathrm{GM}^{+/+}$mice (Figure 5C). In contrast, expression of CD44 was activated in CD8+ T lymphocytes in WT but not in SP-C-GM+/+ mice (Figure 5D). Both CD4+ and CD8+ T lymphocytes were found in low numbers and did not express CD44 in lungs of GM-/- mice (Figure 5A-D). Peripheral activation of T lymphocytes occured in the absence of GM-CSF, as shown by similar activation of CD44 in CD4+ and CD8+ T lymphocyte populations after M. tuberculosis infection (Figure 6A-D). The content of activated CD8+,CD44+ T lymphocytes, however, was higher in WT mice 28 days after infection compared to both $\mathrm{GM} /$ - and SP-C-GM+/+ mice, indicating that peripheral activation of CD8 T cells is not optimal in the absence of GM-CSF. 

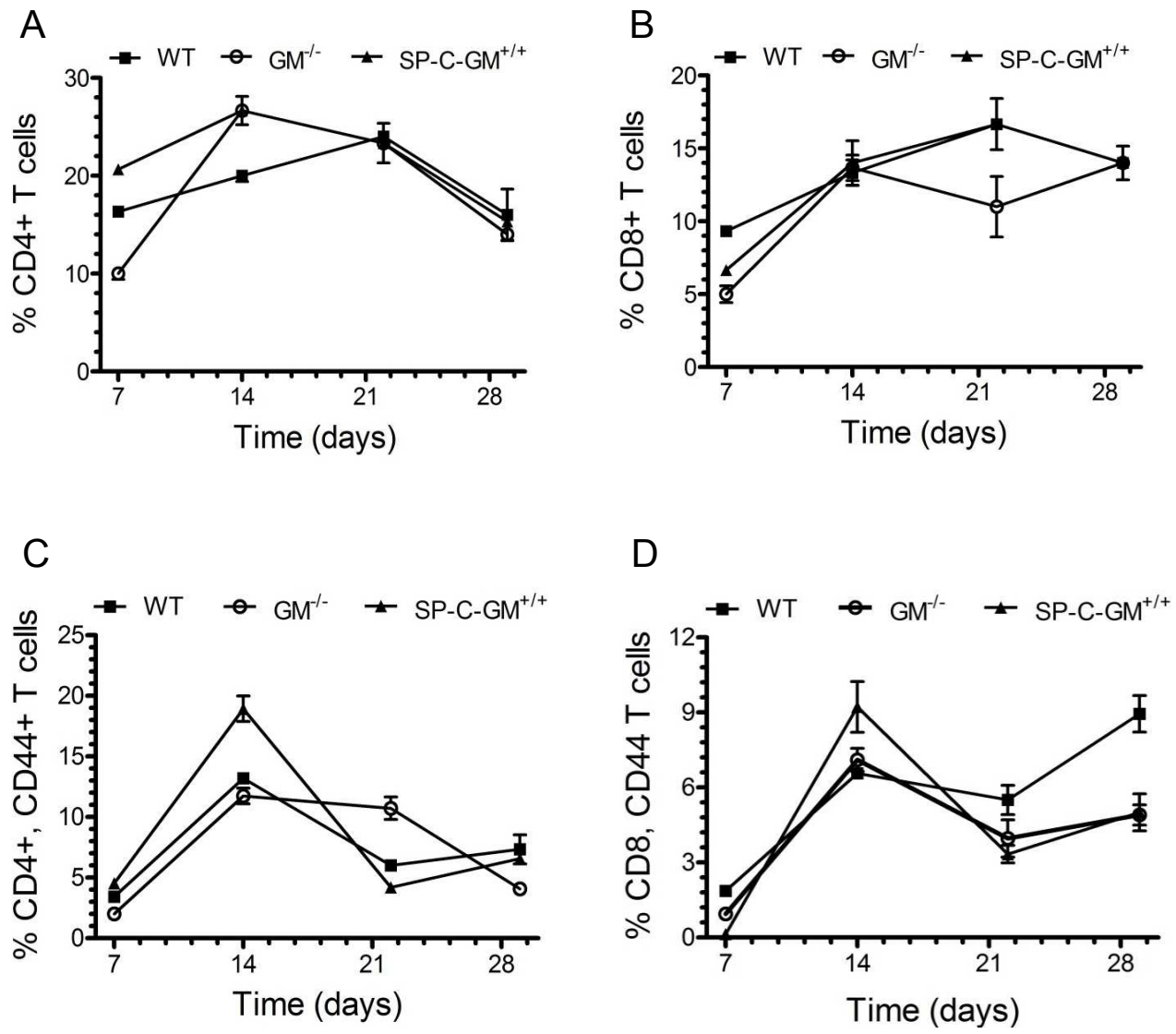

Fig. 6. Effect of lung GM-CSF in activation of T lymphocytes in the spleen. WT, GM-/-, and SPC-GM ${ }^{+/+}$mice were infected with $100 \mathrm{M}$. tuberculosis cfu via aerosol. Lungs were mechanically dispersed into cell suspensions at indicated times after infection and lymphocytes analyzed by flow cytometry. The content of CD4+ (A) and CD8+ (B) T lymphocytes were obtained by gating. Activated CD4+ (C) and CD8+ (D) T lymphocytes were obtained by staining cells with CD44 antibodies. Data are means \pm S.E.M. $n=4$ for all groups.

Surprisingly, 10-fold reduction in M. tuberculosis infection from 100-200 cfu to 10-20 cfu delayed morbidity significantly from 30-40 days weeks to six months in both $\mathrm{GM}-1-$ mice and from 70-90 days to 12 months in SP-C-GM+/+ mice (17). Histological evaluation of $\mathrm{GM}^{-} /-$ lungs 6 months after low dose $M$. tuberculosis infection revealed intra-bronchial obstruction with surfactant rich material and necrotic cellular debris indicating collapse of alveolar spaces into bronchial airways. Interestingly, peribronchial spaces of obstructed airways contained lymphocytic infiltrates, suggesting that cell-mediated immunity against $M$. tuberculosis is abnormal histologically but not impaired in the absence of GM-CSF. On the other hand, the low dose infection in SP-C-GM+/+ mice generated large lymphocytic granulomas similar to WT mice and expansion of foamy macrophages in surrounding 
alveoli contrasting the results following high dose $M$. tuberculosis infection described above $(17,71)$. These findings indicate an important relationship between GM-CSF levels and $M$. tuberculosis infection dose modulating histological remodeling in pulmonary tuberculosis.

\section{Discussion}

Histological studies indicate that GM-CSF facilitates formation of early epithelioid granulomas in lung parenchyma during the innate phase of M. tuberculosis infection. GM-CSF expression is required for the development of interstitial granulomas as indicated by the absence of interstitial lesions in $\mathrm{GM} /$ - mice and formation of enlarged epithelioid lesions in $\mathrm{SP}-\mathrm{C}-\mathrm{GM}^{+/+}$ mice in the first 15 days after $M$. tuberculosis infection. This early histological response involves recruitment of macrophages and other immune cells leading the differentiation of interstitial lesions enriched in epithelioid cells. Initial granuloma formation begins with alveolar deposition of $M$. tuberculosis organisms resulting in not only infection of alveolar macrophages but also trafficking and proliferation of $M$. tuberculosis in interstitial granulomas. In contrast to WT and SP-C-GM-CSF ${ }^{+/+}$mice, alveolar macrophages were the main site of infection in $\mathrm{GM}^{-/-}$ mice, indicating that GM-CSF is not required for infection of alveolar macrophages by $M$. tuberculosis, whereas GM-CSF is required for the early dissemination of $M$. tuberculosis into lung interstitium. Differences in GM-CSF levels, however, did not influence or alter distal dissemination to the spleen (unpublished data), indicating that peripheral and local dissemination of $M$. tuberculosis infection involve different mechanisms. Transport of infected macrophages or infection of epithelial cells may contribute to early interstitial dissemination of M. tuberculosis. GM-CSF-induced differentiation of alveolar macrophages or expression of mycobacterial receptors on alveolar epithelial cells may be required to relocate $M$. tuberculosis from the alveolar lumen to lung interstitium. Previous studies reported that $M$. tuberculosis uses the cell-surface hemagglutinin HBHA to trancytose across alveolar epithelial cells (82). More recently, it was shown that $M$. tuberculosis and its close relative M. marinum spread between cells via the ejectosome (83), an actin-based non-lytic mechanism that requires expression of the ESX-1 secretion system. The ESX-1 secretion system of M. tuberculosis mediates export of the highly immunogenic antigen ESAT-6. Mycobacterial organisms such as $M$. avium and $M$. bovis BCG that lack ESX-1 do not disseminate through ejectosomes. The early epithelioid granuloma drives activation of cell-mediated immunity as indicated by marked induction of IL-12p40 in WT and SP-C-GM ${ }^{+/+}$mice but not in $\mathrm{GM}^{-/-}$mice two weeks after $M$. tuberculosis infection. It is possible that epithelioid macrophages are an intermediate source of M. tuberculosis antigen presentation that dendritic cells acquire en route to lymph nodes, a process that takes two weeks to complete before activation of protective immunity against $M$. tuberculosis. Formation of parenchymal epithelioid lesions leading to activation of IL-12p40 secretion preceded the appearance of lymphocytic granulomas in mucosal and peri-bronchial sites establishing cell-mediated immunity and long-term control of the infection in the lung.

GM-CSF suppresses formation of foamy alveolar macrophages in M. tuberculosis infected lungs. Macrophage-derived foam cells arise by accumulation of intracellular lipids. Macrophage-derived foam cells are a characteristic feature of primary and post-primary tuberculosis lesions in lungs of both mice and humans (84-86). Macrophage foam cells may facilitate resolution of infection with the vaccine strain $M$. tuberculosis BCG (87), but are thought to have pathogenic roles in M. tuberculosis infection. M. tuberculosis cell wall lipids contribute to foam cell formation by inducing accumulation of lipid bodies in macrophages 
$(84,88)$. Foam cells may modify the ability of $M$. tuberculosis as a persistent or a resurgent pathogen during latent $(89,90)$ and post-primary tuberculosis $(86)$, respectively. Lipid bodies that fuse with phago-lysosomes are thought to provide cholesterol and other host lipid nutrients facilitating persistence of M. tuberculosis (90-92). Foamy macrophages, in which $M$. tuberculosis organisms were identified at later stages of infection, were a distinguishing feature of lymphocytic granulomas in WT lungs and SP-C-GM+/+ mice. In the latter case, large lymphocytic granulomas with expansion of foamy alveolar macrophages was present after low but not high dose infection with $M$. tuberculosis. In contrast to WT and SP-C-GM+/+ mice, expansion of foamy macrophages evolving into necrotic granulomas filling alveolar and bronchial spaces was the only lesion that developed three weeks after infection of $\mathrm{GM}-/-$ mice with $M$. tuberculosis infection. Induction of IL-12p40 and IFN $\gamma$ was not abrogated but occurred at late stages of infection apparently providing adequate immunity that prolonged survival at low dose infection with $M$. tuberculosis. Necrotic granulomas obstructing alveolar and bronchial spaces were enriched in pulmonary surfactant. Interestingly, staining surfactant proteins in normal mice indicated that surfactant lipoprotein is actively produced by alveolar type II epithelial within tuberculous granulomas (17). Given the essential and selective role of GM-CSF in degradation of surfactant lipids $(46,58)$, it is reasonable to speculate that foamy macrophages in tuberculosis represent macrophages that have lost the capacity to respond to GM-CSF forming a suitable environment for $M$. tuberculosis to maintain its life cycle in the long term.

\section{Hypothesis}

The model on Figure 7 depicts that differences in GM-CSF levels control the balance between protective and escape mechanisms through which $M$. tuberculosis is either controlled or causes infection transmitting infection to other individuals. The histological presentation of primary tuberculosis at early stage of infection is discerned by three morphologically distinct but interacting processes. GM-CSF is necessary for the development of epithelioid granulomas in lung parenchyma 0-15 days after infection, a period known as the innate phase of the infection. Epithelioid granulomas govern the development of cell-mediated immunity in the form of lymphocytic granulomas which curb proliferation of M. tuberculosis in the lung. Macrophages that lose the ability to respond to GM-CSF constitute the escape mechanism that transitions primary tuberculosis to chronic infection. Foamy macrophages accumulate lipids that may provide a permissive environment for mycobacteria to survive. Foamy macrophages remain in constant interaction with adaptive immune cells preventing mycobacterial proliferation in the long-term. High levels of GM-CSF generated at the chronic or latent stage of tuberculosis may alter polarization of the immune response resulting in reactivation of the infection in foamy macrophages. As a result, development of post-primary tuberculosis may progress to cavities transmitting the disease to other individuals through coughing. At this stage, depending on the cause of GM-CSF secretion, GM-CSF may work to the host's benefit to resorb lipid through recruitment and differentiation of macrophages facilitating resolution of cavitary tuberculosis, as occurs in most individuals with post-primary tuberculosis (93), or promote disease development through inappropriate polarization of the immune response in the lung. At this point it should be noted that BCG immunization in the context of high levels of GM-CSF was associated with Th2 polarization after clearance of BCG (Figure 2). BCG has been highly effective against tuberculosis in children preventing dissemination of the disease that causes 
tuberculous meningitis, but fails to prevent activation of the disease in adults. Millions of children receive BCG vaccination yearly. Differences in lung GM-CSF in endemic populations may contribute to the failure of the BCG vaccine once these individuals become adults and it is

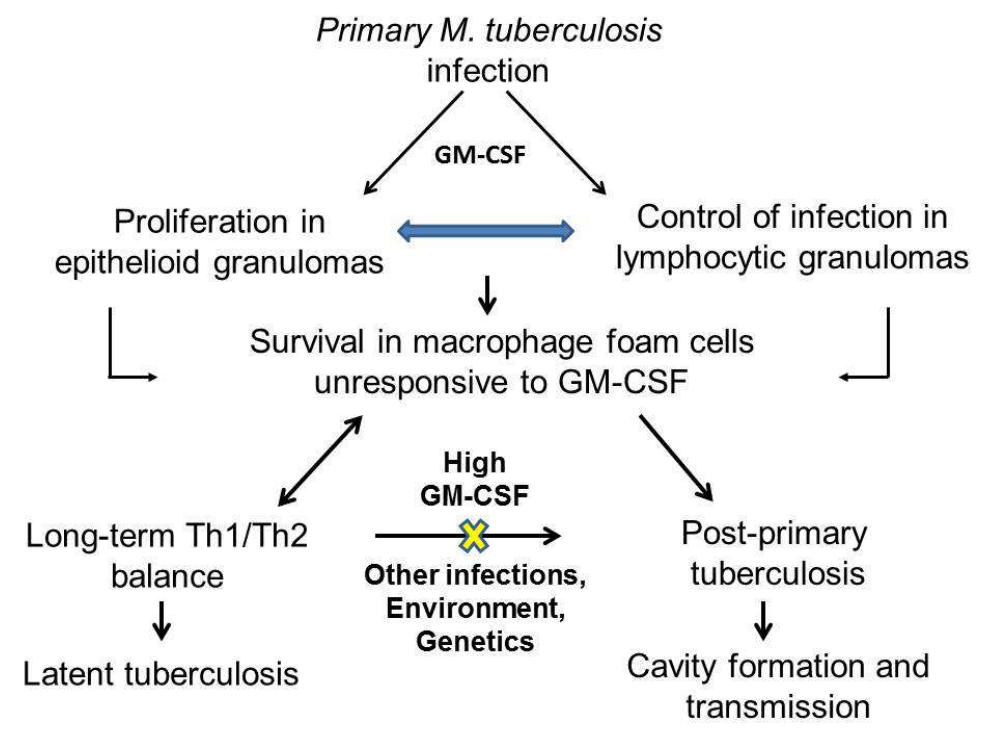

Fig. 7. Hypothesis on the role of GM-CSF in pathogenesis of pulmonary tuberculosis.GMCSF is required for initiation of protective immunity against primary tuberculosis by inducing optimal formation of epithelioid and lymphocytic granulomas. M. tuberculosis survives in foamy macrophages that do not respond to GM-CSF. Long-term adaptive immunity regulates transition to latent tuberculosis by suppressing mycobacterial proliferation in foamy macrophages. Excess production of GM-CSF during latent infection alters the balance of adaptive immunity resulting in reactivation of $M$. tuberculosis infection in foam cells. Reactivation of M. tuberculosis causes development of post-primary tuberculosis and formation of cavities that transmit tuberculosis disease.

not unreasonable to suggest that it could contribute to post-primary tuberculosis, the most common form of the disease in the developing world. Given the hypothesis that latent M. tuberculosis infection hides in foamy macrophages under the incomplete surveillance of cellmediated immunity, the mouse models described here present unique opportunities to test vaccine strategies targeting the infection in its natural host cell.

\section{Methods}

\subsection{Mice}

Specific pathogen-free male or female $\mathrm{C} 57 \mathrm{Bl} / 6$ mice were obtained from Jackson Laboratories (Bar Harbor, ME). The generation C57BL/6 GM-/- and SP-C-GM+/+/GM-/- mice was described previously $(50,94)$. Mice were housed and bred under specific-pathogen free conditions. Mice were transferred to a BSL-3 vivarium for experiments and were used at between 4-6 weeks of age in accordance with IACUC approved protocols. 


\subsection{Bacteria}

Mycobacterium tuberculosis (MTB) H37Rv (\#27294) was from the ATCC repository. The M. bovis BCG strain Tokyo strain S-10 was a kind gift of Dr. Malini Rajagopalan, University of Texas Health Science Center at Tyler. Colonies (CFU) grown on 7H11 agar were subcultured in $7 \mathrm{H} 9$ broth and log phase organisms were harvested 10-12 days later. Bacteria were washed in PBS and sonicated at 5 watts for 15 seconds to disperse organisms and stored in aliquots at $-70{ }^{\circ} \mathrm{C}$ in $70 \%$ glycerol-PBS. One thawed aliquot was diluted ten-fold in PBS and plated for CFU counts on 7H11 agar.

\subsection{Infections of mice}

Pulmonary infections with $1.5 \times 10^{7}$ BCG were established intranasaly as previously described. Aerosol infections were performed in a Middlebrook aerosol exposure chamber (Glascol Inc, Terre Haute, IN). A sonically dispersed suspension of MTB at $10^{6} \mathrm{CFU} / \mathrm{mL}$ in saline was nebulized for $30 \mathrm{~min}$, which implanted around $2.0 \log _{10} \mathrm{CFU} /$ mouse lung. All mouse groups were exposed to the MTB aerosol at the same time. Mice were sacrificed on indicated time points and lungs and spleens were aseptically removed. Organs were homogenized in PBS with $0.05 \%$ Tween- 80 and ten-fold dilutions plated on 7H11 agar for enumeration of CFU counts.

\subsection{Localization of mycobacteria in lungs}

Infected organs were fixed in $10 \%$ formalin and embedded in paraffin. Mycobacteria were visualized using an auramine-rhodamine staining kit (BD Biosciences, San Diego, CA). Fluorescent images were captured using TE 100 inverted microscope equipped with a Cooke Sensicam digital camera (3I imaging Denver, Co). The MTB burden in infected lesions was estimated as fluorescent pixels/microscopic field from six randomly selected microscopic fields by using morphometry tools embedded in Slidebook software (3I imaging, Denver, Co). Tissues were interrogated at 40x magnification.

\subsection{ELISA}

Lung homogenates were filtered using $0.2 \mu$ syringe filters prior to ELISA assays that measured the concentration of IFN $\gamma$, IL-12, IL-10, IL-4, MCP-1, and TNF $\alpha$. All kits were obtained from eBiosciences (San Diego, CA).

\subsection{Flow cytometry}

Single cell suspensions were obtained from lung and spleen. Lungs were perfused with cold sterile phosphate buffered saline (PBS), minced and digested in PBS containing $1 \mathrm{mM}$ EDTA, $100 \mathrm{U} / \mathrm{mL}$ collagenase, $50 \mu \mathrm{g} / \mathrm{ml}$ elastase and $1 \mu \mathrm{g} / \mathrm{ml}$ DNAase (Sigma Alidrich, MO) for 45 min at $37^{\circ} \mathrm{C}$. The digest was then passed through a $0.45 \mu$ nylon mesh to obtain single cell suspensions. The cells were centrifuged and then suspended and stained in FACS buffer (PBS, supplemented with $2 \%$ heat inactivated goat serum, $0.5 \%$ fetal calf serum, $10 \mu \mathrm{g} / \mathrm{ml} \mathrm{Fc} \mathrm{block}$ and $0.02 \%$ azide). The $\mathrm{T}$ cells were stained with conjugated antibodies against the following antigens (BD PharMingen): CD3 (anti-CD3-PE, clone 145.2C11), CD4 (anti-CD4-FITC, clone H129.19), CD8 (anti-CD8-FITC, clone 53-6.7), and CD44 (anti-CD44-PE, clone IM7). Dual 
staining of lymphocytes was accomplished using antibodies to CD4 or CD8 along with antibodies against CD44. Cells were fixed with $2 \%$ paraformaldehyde for $1 \mathrm{~h}$ and analyzed by flow cytometry using CellQuest software (BD Immunocytometry Systems, San Jose, CA). Cells were gated on the lymphocyte and monocytes by forward and side scatter.

\subsection{Statistics}

Graphing and statistical analysis was accomplished using Graphpad Prism 4.0 software (www.graphpad.com). Statistical comparisons were assessed by two-way ANOVA, and differences were considered significant at $\mathrm{p}<0.05$.

\section{Acknowledgements}

This work was supported in part through NIH grants HL068127 and HL068520 and the Pott's Memorial Foundation award (ZCC). The authors wish to thank Dr Robert L. Hunter, Chair of Pathology, Department of Pathology and Laboratary Medicine, University of Texas Health Sciences Center at Houston for inspiring discussions over an extensive tissue collection on pathological manifestations of human tuberculosis.

\section{References}

[1] Dorhoi, A., S. T. Reece, and S. H. Kaufmann. 2011. For better or for worse: the immune response against Mycobacterium tuberculosis balances pathology and protection. Immunological reviews 240:235-251.

[2] Hunter, R. L., C. Jagannath, and J. K. Actor. 2007. Pathology of postprimary tuberculosis in humans and mice: contradiction of long-held beliefs. Tuberculosis 87:267-278.

[3] Lawn, S. D., and A. I. Zumla. 2011. Tuberculosis. Lancet 378:57-72.

[4] Dye, C., and B. G. Williams. 2010. The population dynamics and control of tuberculosis. Science 328:856-861.

[5] Hunter, R. L. 2011. Pathology of post primary tuberculosis of the lung: An illustrated critical review. Tuberculosis.

[6] Rook, G. A., K. Dheda, and A. Zumla. 2006. Immune systems in developed and developing countries; implications for the design of vaccines that will work where BCG does not. Tuberculosis 86:152-162.

[7] Kwan, C. K., and J. D. Ernst. 2011. HIV and tuberculosis: a deadly human syndemic. Clinical microbiology reviews 24:351-376.

[8] Koul, A., E. Arnoult, N. Lounis, J. Guillemont, and K. Andries. 2011. The challenge of new drug discovery for tuberculosis. Nature 469:483-490.

[9] Tiemersma, E. W., M. J. van der Werf, M. W. Borgdorff, B. G. Williams, and N. J. Nagelkerke. 2011. Natural history of tuberculosis: duration and fatality of untreated pulmonary tuberculosis in HIV negative patients: a systematic review. PloS one 6:e17601.

[10] Russell, D. G., C. E. Barry, 3rd, and J. L. Flynn. 2010. Tuberculosis: what we don't know can, and does, hurt us. Science 328:852-856. 
[11] Barry, C. E., 3rd, H. I. Boshoff, V. Dartois, T. Dick, S. Ehrt, J. Flynn, D. Schnappinger, R. J. Wilkinson, and D. Young. 2009. The spectrum of latent tuberculosis: rethinking the biology and intervention strategies. Nat Rev Microbiol 7:845-855.

[12] Ehlers, S. 2009. Lazy, dynamic or minimally recrudescent? On the elusive nature and location of the mycobacterium responsible for latent tuberculosis. Infection 37:8795.

[13] Ulrichs, T., and S. H. Kaufmann. 2006. New insights into the function of granulomas in human tuberculosis. J Pathol 208:261-269.

[14] Kondratieva, E., N. Logunova, K. Majorov, M. Averbakh, and A. Apt. 2010. Host genetics in granuloma formation: human-like lung pathology in mice with reciprocal genetic susceptibility to $\mathrm{M}$. tuberculosis and $\mathrm{M}$. avium. PloS one 5:e10515.

[15] Russell, D. G. 2007. Who puts the tubercle in tuberculosis? Nat Rev Microbiol 5:39-47.

[16] Flynn, J. L., and J. Chan. 2003. Immune evasion by Mycobacterium tuberculosis: living with the enemy. Current opinion in immunology 15:450-455.

[17] Chroneos, Z. C., K. Midde, Z. Sever-Chroneos, and C. Jagannath. 2009. Pulmonary surfactant and tuberculosis. Tuberculosis 89 Suppl 1:S10-14.

[18] Volkman, H. E., T. C. Pozos, J. Zheng, J. M. Davis, J. F. Rawls, and L. Ramakrishnan. 2010. Tuberculous granuloma induction via interaction of a bacterial secreted protein with host epithelium. Science 327:466-469.

[19] Krishnan, N., B. D. Robertson, and G. Thwaites. 2010. The mechanisms and consequences of the extra-pulmonary dissemination of Mycobacterium tuberculosis. Tuberculosis 90:361-366.

[20] Debbabi, H., S. Ghosh, A. B. Kamath, J. Alt, D. E. Demello, S. Dunsmore, and S. M. Behar. 2005. Primary type II alveolar epithelial cells present microbial antigens to antigen-specific CD4+ T cells. Am J Physiol Lung Cell Mol Physiol 289:L274-279.

[21] Urdahl, K. B., S. Shafiani, and J. D. Ernst. 2011. Initiation and regulation of T-cell responses in tuberculosis. Mucosal Immunol 4:288-293.

[22] Mihret, A., G. Mamo, M. Tafesse, A. Hailu, and S. Parida. 2011. Dendritic Cells Activate and Mature after Infection with Mycobacterium tuberculosis. BMC Res Notes 4:247.

[23] Bermudez, L. E., F. J. Sangari, P. Kolonoski, M. Petrofsky, and J. Goodman. 2002. The efficiency of the translocation of Mycobacterium tuberculosis across a bilayer of epithelial and endothelial cells as a model of the alveolar wall is a consequence of transport within mononuclear phagocytes and invasion of alveolar epithelial cells. Infection and immunity 70:140-146.

[24] Davis, J. M., and L. Ramakrishnan. 2009. The role of the granuloma in expansion and dissemination of early tuberculous infection. Cell 136:37-49.

[25] Cosma, C. L., O. Humbert, D. R. Sherman, and L. Ramakrishnan. 2008. Trafficking of superinfecting Mycobacterium organisms into established granulomas occurs in mammals and is independent of the Erp and ESX-1 mycobacterial virulence loci. The Journal of infectious diseases 198:1851-1855. 
[26] Clay, H., H. E. Volkman, and L. Ramakrishnan. 2008. Tumor necrosis factor signaling mediates resistance to mycobacteria by inhibiting bacterial growth and macrophage death. Immunity 29:283-294.

[27] Cooper, A. M., K. D. Mayer-Barber, and A. Sher. 2011. Role of innate cytokines in mycobacterial infection. Mucosal Immunol 4:252-260.

[28] North, R. J., and Y. J. Jung. 2004. Immunity to tuberculosis. Annu Rev Immunol 22:599623.

[29] Harris, J., and J. Keane. 2010. How tumour necrosis factor blockers interfere with tuberculosis immunity. Clinical and experimental immunology 161:1-9.

[30] Via, L. E., P. L. Lin, S. M. Ray, J. Carrillo, S. S. Allen, S. Y. Eum, K. Taylor, E. Klein, U. Manjunatha, J. Gonzales, E. G. Lee, S. K. Park, J. A. Raleigh, S. N. Cho, D. N. McMurray, J. L. Flynn, and C. E. Barry, 3rd. 2008. Tuberculous granulomas are hypoxic in guinea pigs, rabbits, and nonhuman primates. Infection and immunity 76:2333-2340.

[31] Tsai, M. C., S. Chakravarty, G. Zhu, J. Xu, K. Tanaka, C. Koch, J. Tufariello, J. Flynn, and J. Chan. 2006. Characterization of the tuberculous granuloma in murine and human lungs: cellular composition and relative tissue oxygen tension. Cell Microbiol 8:218232.

[32] Rook, G. A. 2007. Th2 cytokines in susceptibility to tuberculosis. Curr Mol Med 7:327337.

[33] Rook, G. A., K. Dheda, and A. Zumla. 2005. Immune responses to tuberculosis in developing countries: implications for new vaccines. Nature reviews. Immunology 5:661-667.

[34] Perry, S., R. Hussain, and J. Parsonnet. 2011. The impact of mucosal infections on acquisition and progression of tuberculosis. Mucosal Immunol 4:246-251.

[35] Potian, J. A., W. Rafi, K. Bhatt, A. McBride, W. C. Gause, and P. Salgame. 2011. Preexisting helminth infection induces inhibition of innate pulmonary antituberculosis defense by engaging the IL-4 receptor pathway. J Exp Med 208:18631874.

[36] Scriba, T. J., M. Tameris, N. Mansoor, E. Smit, L. van der Merwe, F. Isaacs, A. Keyser, S. Moyo, N. Brittain, A. Lawrie, S. Gelderbloem, A. Veldsman, M. Hatherill, A. Hawkridge, A. V. Hill, G. D. Hussey, H. Mahomed, H. McShane, and W. A. Hanekom. 2010. Modified vaccinia Ankara-expressing Ag85A, a novel tuberculosis vaccine, is safe in adolescents and children, and induces polyfunctional CD4+ T cells. European journal of immunology 40:279-290.

[37] Andersen, P., and T. M. Doherty. 2005. The success and failure of BCG - implications for a novel tuberculosis vaccine. Nat Rev Microbiol 3:656-662.

[38] Kaufmann, S. H. 2011. Fact and fiction in tuberculosis vaccine research: 10 years later. Lancet Infect Dis 11:633-640.

[39] Kaufmann, S. H. 2010. Learning from natural infection for rational tuberculosis vaccine design: from basic science to translational research. Hum Vaccin 6:614-618.

[40] Yang, X., L. Bao, and Y. Deng. 2011. A novel recombinant Mycobacterium bovis bacillus Calmette-Guerin strain expressing human granulocyte macrophage colony-stimulating factor and Mycobacterium tuberculosis early secretory 
antigenic target 6 complex augments Th1 immunity. Acta Biochim Biophys Sin (Shanghai) 43:511-518.

[41] Nambiar, J. K., A. A. Ryan, C. U. Kong, W. J. Britton, and J. A. Triccas. 2010. Modulation of pulmonary DC function by vaccine-encoded GM-CSF enhances protective immunity against Mycobacterium tuberculosis infection. European journal of immunology 40:153-161.

[42] Ryan, A. A., T. M. Wozniak, E. Shklovskaya, M. A. O'Donnell, B. Fazekas de St Groth, W. J. Britton, and J. A. Triccas. 2007. Improved protection against disseminated tuberculosis by Mycobacterium bovis bacillus Calmette-Guerin secreting murine GM-CSF is associated with expansion and activation of APCs. Journal of immunology 179:8418-8424.

[43] Dou, J., Q. Tang, F. Yu, H. Yang, F. Zhao, W. Xu, J. Wang, W. Hu, K. Hu, C. Liou, X. Feng He, and Y. Wang. 2010. Investigation of immunogenic effect of the BCG priming and Ag85A- GM-CSF boosting in Balb/c mice model. Immunobiology 215:133-142.

[44] Zhang, X., M. Divangahi, P. Ngai, M. Santosuosso, J. Millar, A. Zganiacz, J. Wang, J. Bramson, and Z. Xing. 2007. Intramuscular immunization with a monogenic plasmid DNA tuberculosis vaccine: Enhanced immunogenicity by electroporation and co-expression of GM-CSF transgene. Vaccine 25:1342-1352.

[45] Makino, M., Y. Maeda, M. Kai, T. Tamura, and T. Mukai. 2009. GM-CSF-mediated T-cell activation by macrophages infected with recombinant BCG that secretes major membrane protein-II of Mycobacterium leprae. FEMS immunology and medical microbiology 55:39-46.

[46] Carey, B., and B. C. Trapnell. 2010. The molecular basis of pulmonary alveolar proteinosis. Clinical immunology 135:223-235.

[47] Shibata, Y., P. Y. Berclaz, Z. C. Chroneos, M. Yoshida, J. A. Whitsett, and B. C. Trapnell. 2001. GM-CSF regulates alveolar macrophage differentiation and innate immunity in the lung through PU.1. Immunity 15:557-567.

[48] Hercus, T. R., D. Thomas, M. A. Guthridge, P. G. Ekert, J. King-Scott, M. W. Parker, and A. F. Lopez. 2009. The granulocyte-macrophage colony-stimulating factor receptor: linking its structure to cell signaling and its role in disease. Blood 114:1289-1298.

[49] Bonfield, T. L., B. Raychaudhuri, A. Malur, S. Abraham, B. C. Trapnell, M. S. Kavuru, and M. J. Thomassen. 2003. PU.1 regulation of human alveolar macrophage differentiation requires granulocyte-macrophage colony-stimulating factor. American journal of physiology. Lung cellular and molecular physiology 285:L1132-1136.

[50] Dranoff, G., A. D. Crawford, M. Sadelain, B. Ream, A. Rashid, R. T. Bronson, G. R. Dickersin, C. J. Bachurski, E. L. Mark, J. A. Whitsett, and et al. 1994. Involvement of granulocyte-macrophage colony-stimulating factor in pulmonary homeostasis. Science 264:713-716.

[51] Stanley, E., G. J. Lieschke, D. Grail, D. Metcalf, G. Hodgson, J. A. Gall, D. W. Maher, J. Cebon, V. Sinickas, and A. R. Dunn. 1994. Granulocyte/macrophage colonystimulating factor-deficient mice show no major perturbation of hematopoiesis but develop a characteristic pulmonary pathology. Proc Natl Acad Sci U S A 91:55925596 . 
[52] Yoshida, M., M. Ikegami, J. A. Reed, Z. C. Chroneos, and J. A. Whitsett. 2001. GM-CSF regulates protein and lipid catabolism by alveolar macrophages. American journal of physiology. Lung cellular and molecular physiology 280:L379-386.

[53] Ikegami, M., T. Ueda, W. Hull, J. A. Whitsett, R. C. Mulligan, G. Dranoff, and A. H. Jobe. 1996. Surfactant metabolism in transgenic mice after granulocyte macrophage-colony stimulating factor ablation. Am J Physiol 270:L650-658.

[54] Gurel, O., M. Ikegami, Z. C. Chroneos, and A. H. Jobe. 2001. Macrophage and type II cell catabolism of SP-A and saturated phosphatidylcholine in mouse lungs. American journal of physiology. Lung cellular and molecular physiology 280:L1266-1272.

[55] Berclaz, P. Y., B. Carey, M. D. Fillipi, K. Wernke-Dollries, N. Geraci, S. Cush, T. Richardson, J. Kitzmiller, M. O'Connor, C. Hermoyian, T. Korfhagen, J. A. Whitsett, and B. C. Trapnell. 2007. GM-CSF regulates a PU.1-dependent transcriptional program determining the pulmonary response to LPS. American journal of respiratory cell and molecular biology 36:114-121.

[56] Carey, B., M. K. Staudt, D. Bonaminio, J. C. van der Loo, and B. C. Trapnell. 2007. PU.1 redirects adenovirus to lysosomes in alveolar macrophages, uncoupling internalization from infection. Journal of immunology 178:2440-2447.

[57] Berclaz, P. Y., Y. Shibata, J. A. Whitsett, and B. C. Trapnell. 2002. GM-CSF, via PU.1, regulates alveolar macrophage Fcgamma R-mediated phagocytosis and the IL18/IFN-gamma -mediated molecular connection between innate and adaptive immunity in the lung. Blood 100:4193-4200.

[58] Baker, A. D., A. Malur, B. P. Barna, S. Ghosh, M. S. Kavuru, A. G. Malur, and M. J. Thomassen. 2010. Targeted PPAR\{gamma\} deficiency in alveolar macrophages disrupts surfactant catabolism. J Lipid Res 51:1325-1331.

[59] Bonfield, T. L., M. J. Thomassen, C. F. Farver, S. Abraham, M. T. Koloze, X. Zhang, D. M. Mosser, and D. A. Culver. 2008. Peroxisome proliferator-activated receptorgamma regulates the expression of alveolar macrophage macrophage colonystimulating factor. J Immunol 181:235-242.

[60] Bonfield, T. L., C. F. Farver, B. P. Barna, A. Malur, S. Abraham, B. Raychaudhuri, M. S. Kavuru, and M. J. Thomassen. 2003. Peroxisome proliferator-activated receptorgamma is deficient in alveolar macrophages from patients with alveolar proteinosis. Am J Respir Cell Mol Biol 29:677-682.

[61] Rate, A., J. W. Upham, A. Bosco, K. L. McKenna, and P. G. Holt. 2009. Airway epithelial cells regulate the functional phenotype of locally differentiating dendritic cells: implications for the pathogenesis of infectious and allergic airway disease. $J$ Immunol 182:72-83.

[62] Bilyk, N., and P. G. Holt. 1995. Cytokine modulation of the immunosuppressive phenotype of pulmonary alveolar macrophage populations. Immunology 86:231-237.

[63] Bilyk, N., and P. G. Holt. 1993. Inhibition of the immunosuppressive activity of resident pulmonary alveolar macrophages by granulocyte/macrophage colony-stimulating factor. J Exp Med 177:1773-1777.

[64] Fleetwood, A. J., A. D. Cook, and J. A. Hamilton. 2005. Functions of granulocytemacrophage colony-stimulating factor. Crit Rev Immunol 25:405-428. 
[65] Worgall, S., R. Singh, P. L. Leopold, R. J. Kaner, N. R. Hackett, N. Topf, M. A. Moore, and R. G. Crystal. 1999. Selective expansion of alveolar macrophages in vivo by adenovirus-mediated transfer of the murine granulocyte-macrophage colonystimulating factor cDNA. Blood 93:655-666.

[66] Huffman Reed, J. A., W. R. Rice, Z. K. Zsengeller, S. E. Wert, G. Dranoff, and J. A. Whitsett. 1997. GM-CSF enhances lung growth and causes alveolar type II epithelial cell hyperplasia in transgenic mice. Am J Physiol 273:L715-725.

[67] Tournier, J. N., and M. Mohamadzadeh. 2008. Microenvironmental impact on lung cell homeostasis and immunity during infection. Expert Rev Vaccines 7:457-466.

[68] Chroneos, Z. C., Z. Sever-Chroneos, and V. L. Shepherd. 2010. Pulmonary surfactant: an immunological perspective. Cell Physiol Biochem 25:13-26.

[69] Samten, B., J. C. Townsend, Z. Sever-Chroneos, V. Pasquinelli, P. F. Barnes, and Z. C. Chroneos. 2008. An antibody against the surfactant protein A (SP-A)-binding domain of the SP-A receptor inhibits $\mathrm{T}$ cell-mediated immune responses to Mycobacterium tuberculosis. Journal of leukocyte biology 84:115-123.

[70] Cakarova, L., L. M. Marsh, J. Wilhelm, K. Mayer, F. Grimminger, W. Seeger, J. Lohmeyer, and S. Herold. 2009. Macrophage tumor necrosis factor-alpha induces epithelial expression of granulocyte-macrophage colony-stimulating factor: impact on alveolar epithelial repair. Am J Respir Crit Care Med 180:521-532.

[71] Szeliga, J., D. S. Daniel, C. H. Yang, Z. Sever-Chroneos, C. Jagannath, and Z. C. Chroneos. 2008. Granulocyte-macrophage colony stimulating factor-mediated innate responses in tuberculosis. Tuberculosis 88:7-20.

[72] Gonzalez-Juarrero, M., J. M. Hattle, A. Izzo, A. P. Junqueira-Kipnis, T. S. Shim, B. C. Trapnell, A. M. Cooper, and I. M. Orme. 2005. Disruption of granulocyte macrophage-colony stimulating factor production in the lungs severely affects the ability of mice to control Mycobacterium tuberculosis infection. Journal of leukocyte biology 77:914-922.

[73] Alaniz, R. C., S. Sandall, E. K. Thomas, and C. B. Wilson. 2004. Increased dendritic cell numbers impair protective immunity to intracellular bacteria despite augmenting antigen-specific CD8+ T lymphocyte responses. J Immunol 172:3725-3735.

[74] Szeliga, J., J. Jordan, C. H. Yang, Z. Sever-Chroneos, and Z. C. Chroneos. 2005. Bacterial expression of recombinant MyoXVIIIA domains. Analytical biochemistry 346:179-181.

[75] Zhan, Y., and C. Cheers. 2000. Haemopoiesis in mice genetically lacking granulocytemacrophage colony stimulating factor during chronic infection with Mycobacterium avium. Immunology and cell biology 78:118-123.

[76] Pompei, L., S. Jang, B. Zamlynny, S. Ravikumar, A. McBride, S. P. Hickman, and P. Salgame. 2007. Disparity in IL-12 release in dendritic cells and macrophages in response to Mycobacterium tuberculosis is due to use of distinct TLRs. Journal of immunology 178:5192-5199.

[77] Bafica, A., C. A. Scanga, C. Serhan, F. Machado, S. White, A. Sher, and J. Aliberti. 2005. Host control of Mycobacterium tuberculosis is regulated by 5-lipoxygenasedependent lipoxin production. The Journal of clinical investigation 115:1601-1606. 
[78] Frahm, M., N. D. Goswami, K. Owzar, E. Hecker, A. Mosher, E. Cadogan, P. Nahid, G. Ferrari, and J. E. Stout. 2011. Discriminating between latent and active tuberculosis with multiple biomarker responses. Tuberculosis 91:250-256.

[79] Ganachari, M., J. A. Ruiz-Morales, J. C. Gomez de la Torre Pretell, J. Dinh, J. Granados, and P. O. Flores-Villanueva. 2010. Joint effect of MCP-1 genotype GG and MMP-1 genotype $2 \mathrm{G} / 2 \mathrm{G}$ increases the likelihood of developing pulmonary tuberculosis in BCG-vaccinated individuals. PloS one 5:e8881.

[80] Flores-Villanueva, P. O., J. A. Ruiz-Morales, C. H. Song, L. M. Flores, E. K. Jo, M. Montano, P. F. Barnes, M. Selman, and J. Granados. 2005. A functional promoter polymorphism in monocyte chemoattractant protein-1 is associated with increased susceptibility to pulmonary tuberculosis. J Exp Med 202:1649-1658.

[81] Intemann, C. D., T. Thye, B. Forster, E. Owusu-Dabo, J. Gyapong, R. D. Horstmann, and C. G. Meyer. 2011. MCP1 haplotypes associated with protection from pulmonary tuberculosis. BMC Genet 12:34.

[82] Menozzi, F. D., V. M. Reddy, D. Cayet, D. Raze, A. S. Debrie, M. P. Dehouck, R. Cecchelli, and C. Locht. 2006. Mycobacterium tuberculosis heparin-binding haemagglutinin adhesin (HBHA) triggers receptor-mediated transcytosis without altering the integrity of tight junctions. Microbes and infection / Institut Pasteur 8:1-9.

[83] Hagedorn, M., K. H. Rohde, D. G. Russell, and T. Soldati. 2009. Infection by tubercular mycobacteria is spread by nonlytic ejection from their amoeba hosts. Science 323:1729-1733.

[84] Caceres, N., G. Tapia, I. Ojanguren, F. Altare, O. Gil, S. Pinto, C. Vilaplana, and P. J. Cardona. 2009. Evolution of foamy macrophages in the pulmonary granulomas of experimental tuberculosis models. Tuberculosis (Edinb) 89:175-182.

[85] Russell, D. G., P. J. Cardona, M. J. Kim, S. Allain, and F. Altare. 2009. Foamy macrophages and the progression of the human tuberculosis granuloma. Nat Immunol 10:943-948.

[86] Hunter, R. L., C. Jagannath, and J. K. Actor. 2007. Pathology of postprimary tuberculosis in humans and mice: contradiction of long-held beliefs. Tuberculosis (Edinb) 87:267278.

[87] Fulton, S. A., T. D. Martin, R. W. Redline, and W. Henry Boom. 2000. Pulmonary immune responses during primary mycobacterium bovis- Calmette-Guerin bacillus infection in C57Bl/6 mice. American journal of respiratory cell and molecular biology 22:333-343.

[88] Korf, J. E., G. Pynaert, K. Tournoy, T. Boonefaes, A. Van Oosterhout, D. Ginneberge, A. Haegeman, J. A. Verschoor, P. De Baetselier, and J. Grooten. 2006. Macrophage reprogramming by mycolic acid promotes a tolerogenic response in experimental asthma. American journal of respiratory and critical care medicine 174:152-160.

[89] Peyron, P., J. Vaubourgeix, Y. Poquet, F. Levillain, C. Botanch, F. Bardou, M. Daffe, J. F. Emile, B. Marchou, P. J. Cardona, C. de Chastellier, and F. Altare. 2008. Foamy macrophages from tuberculous patients' granulomas constitute a nutrient-rich reservoir for M. tuberculosis persistence. PLoS Pathog 4:e1000204.

[90] Pandey, A. K., and C. M. Sassetti. 2008. Mycobacterial persistence requires the utilization of host cholesterol. Proc Natl Acad Sci U S A 105:4376-4380. 
[91] Brzostek, A., B. Dziadek, A. Rumijowska-Galewicz, J. Pawelczyk, and J. Dziadek. 2007. Cholesterol oxidase is required for virulence of Mycobacterium tuberculosis. FEMS Microbiol Lett 275:106-112.

[92] Av-Gay, Y., and R. Sobouti. 2000. Cholesterol is accumulated by mycobacteria but its degradation is limited to non-pathogenic fast-growing mycobacteria. Can J Microbiol 46:826-831.

[93] Welsh, K. J., S. A. Risin, J. K. Actor, and R. L. Hunter. 2011. Immunopathology of postprimary tuberculosis: increased T-regulatory cells and DEC-205-positive foamy macrophages in cavitary lesions. Clin Dev Immunol 2011:307631.

[94] Huffman, J. A., W. M. Hull, G. Dranoff, R. C. Mulligan, and J. A. Whitsett. 1996. Pulmonary epithelial cell expression of GM-CSF corrects the alveolar proteinosis in GM-CSF-deficient mice. J Clin Invest 97:649-655. 


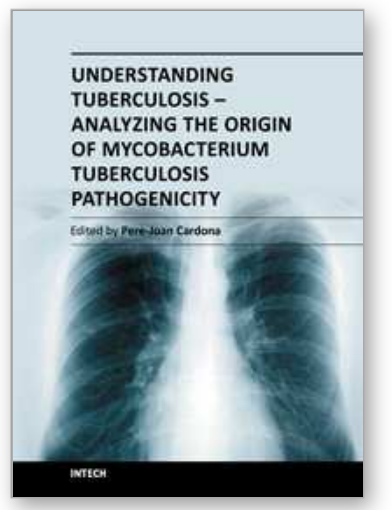

\section{Understanding Tuberculosis - Analyzing the Origin of Mycobacterium Tuberculosis Pathogenicity \\ Edited by Dr. Pere-Joan Cardona}

ISBN 978-953-307-942-4

Hard cover, 560 pages

Publisher InTech

Published online 24, February, 2012

Published in print edition February, 2012

Mycobacterium tuberculosis in an attempt to understand the extent to which the bacilli has adapted itself to the host and to its final target. On the other hand, there is a section in which other specialists discuss how to manipulate this immune response to obtain innovative prophylactic and therapeutic approaches to truncate the intimal co-evolution between Mycobacterium tuberculosis and the Homo sapiens.

\section{How to reference}

In order to correctly reference this scholarly work, feel free to copy and paste the following:

Zissis C. Chroneos and Chinnaswamy Jagannath (2012). Immunoregulatory Role of GM-CSF in Pulmonary Tuberculosis, Understanding Tuberculosis - Analyzing the Origin of Mycobacterium Tuberculosis Pathogenicity, Dr. Pere-Joan Cardona (Ed.), ISBN: 978-953-307-942-4, InTech, Available from: http://www.intechopen.com/books/understanding-tuberculosis-analyzing-the-origin-of-mycobacteriumtuberculosis-pathogenicity/immunoregulatory-role-of-gm-csf-in-pulmonary-tuberculosis

\section{INTECH}

open science | open minds

\section{InTech Europe}

University Campus STeP Ri

Slavka Krautzeka 83/A

51000 Rijeka, Croatia

Phone: +385 (51) 770447

Fax: +385 (51) 686166

www.intechopen.com

\section{InTech China}

Unit 405, Office Block, Hotel Equatorial Shanghai

No.65, Yan An Road (West), Shanghai, 200040, China

中国上海市延安西路65号上海国际贵都大饭店办公楼 405 单元

Phone: +86-21-62489820

Fax: $+86-21-62489821$ 
(C) 2012 The Author(s). Licensee IntechOpen. This is an open access article distributed under the terms of the Creative Commons Attribution 3.0 License, which permits unrestricted use, distribution, and reproduction in any medium, provided the original work is properly cited. 